\title{
A!
}

This is an electronic reprint of the original article.

This reprint may differ from the original in pagination and typographic detail.

Comincioli, Elena; Chirico, Alice; Masoodian, Masood

\section{Improving the Language of Designing for Ageing}

Published in:

Human-Computer Interaction - INTERACT 2021 - 18th IFIP TC 13 International Conference, Proceedings

DOI:

10.1007/978-3-030-85616-8_24

Published: $26 / 08 / 2021$

Document Version

Peer reviewed version

Please cite the original version:

Comincioli, E., Chirico, A., \& Masoodian, M. (2021). Improving the Language of Designing for Ageing. In C. Ardito, R. Lanzilotti, A. Mälizia, H. Petrie, A. Piccinno, G. Desolda, \& K. Inkpen (Eds.), Human-Computer Interaction - INTERACT 2021 - 18th IFIP TC 13 International Conference, Proceedings (pp. 405-425). (Lecture Notes in Computer Science (including subseries Lecture Notes in Artificial Intelligence and Lecture Notes in Bioinformatics); Vol. 12933 LNCS). SPRINGER. https://doi.org/10.1007/978-3-030-85616-8_24

This material is protected by copyright and other intellectual property rights, and duplication or sale of all or part of any of the repository collections is not permitted, except that material may be duplicated by you for your research use or educational purposes in electronic or print form. You must obtain permission for any other use. Electronic or print copies may not be offered, whether for sale or otherwise to anyone who is not an authorised user. 


\title{
Improving the language of designing for ageing
}

\author{
Elena Comincioli, Alice Author ${ }^{2}$, Masood Masoodian ${ }^{1}$ \\ ${ }^{1}$ School of Arts, Design and Architecture, Aalto University, Espoo, Finland \\ \{elena.comincioli, masood.masoodian\} @springer.com \\ ${ }^{2}$ Springer Heidelberg, Tiergartenstr. 17, 69121 Heidelberg, Italy \\ lncs @springer.com
}

\begin{abstract}
In response to an increasingly ageing world population, the World Health Organization has recently proposed a new framework - called Healthy Ageing - to better cater to older adults' life needs and desires. This framework calls for transdisciplinary approaches to answer the challenges and opportunities posed by an ageing society. Following this framework, it is argued that the first step to accomplishing the goals of Healthy Ageing is to address the existing biases and stereotypes in the language used for addressing ageing issues. In this paper, we propose a series of linguistic guidelines that can help improve the lexicon used to talk about ageing in design research and practice, by countering many subconscious ageist biases and stereotypes. Ageism, especially in its implicit form, is a pervasive negative force that can affect not only design practitioners and researchers but also older adults, who often use ageist language to describe themselves. The proposed guidelines would also help the "false friends" of ageing people, who may be using apparently innocuous words, terminology, and remarks to refer to ageing, without perhaps realising the underlying ageist attitudes and stereotypes hidden in their used language. Overall, we aim to foster a change in design researchers' and practitioners' perspective on ageing, by paving the way for a transdisciplinary discourse on designing for ageing, which could then be further expanded and explored to eliminate ageism in design.
\end{abstract}

Keywords: Design for ageing, ageism, older adults, ageing population.

\section{Introduction}

It is widely known that the world population is rapidly ageing. If we look at our social circles, we can often find someone we know who is over 100 years old, or at least past 90 [13]. This is because the life expectancy, especially in Western countries, is on the rise [63]. For researchers in many different fields investigating various aspects of ageing, this demographic change poses exciting opportunities due to ageing populations' specific characteristics. However, ageing is a complex topic that calls for researchers' efforts from different disciplines [60]. Beyond the domains of gerontology, medicine, and ageing studies, other fields such as psychology, human factors, ICT and design are also concerned with ageing.

Interaction Design - a field grounded in human-centred approaches [55] - can also clearly contribute to further research in this area. Over the years, the relationships between various technologies and older adults (OA) have been investigated through a 
large number of proposed designs, interventions and case studies. In this context, the ageing-related factors have generally been considered from mainly two perspectives, ageing as: 1) a source of problems which need to be solved, or 2) a natural process that can be positively targeted and improved. It is important to note that in Interaction Design both of these perspectives carry several nuances. When ageing is seen from the first perspective, researchers primarily focus on the problems of socialisation (e.g. targeting social isolation), deficits (e.g. investigating the decline of specific abilities), health economics (e.g. investigating the care costs associated with ageing), or homogeneity (e.g. starting from a generalisation of the target audience) [55]. On the other hand, when ageing is seen from the second perspective, researchers tend to focus their attention on the lived individual experiences of older adults, and as such, the idea of what constitutes successful ageing is challenged and shaped, with older adults themselves being actively included in the design discourse and process [11, 16, 20, 21, 55].

Designing for older adults by taking this second perspective requires a transdisciplinary approach, with contributions from different fields, and involving older adults in the design process. The success of such an approach, however, is mostly dependent on the use of a shared language by those involved - often coming from divergent fields which is devoid of any of the explicit or implicit stereotypes and biases towards ageing, generally found in most design approaches taken based on the first perspective. In this paper, we propose a series of linguistic guidelines that target many implicit ageist biases and stereotypes commonly used in design fields to talk about ageing. We base this approach on Healthy Ageing, as proposed by the World Health Organization [45, 60].

\section{The paradigm of Healthy Ageing}

Healthy Ageing (HA) is one of the recurring terminologies present in many research articles investigating ageing. While this terminology has started to appear in research literature at least since the year 2000, its meaning has been evolving over the years, along with the evolution of the meaning of health itself. Although we all may have a personal understanding of what a healthy person is, or what a healthy diet or a healthy lifestyle might be, there is an ongoing debate aimed at better defining the meaning of health in a more rigorous way [50]. We can summarise this debate around health by looking at two alternative interpretations. The first of which revolves around the idea of health as the absence of diseases. The second one, most recently put forward by the World Health Organization (WHO), frames health as "a state of complete physical, mental and social wellbeing and not merely the absence of disease or infirmity" [59]. These two perspectives have strongly influenced the fields of HCI and Interaction Design. For instance, when the adjective "healthy" has been associated with the noun "ageing" following the first interpretation, it has been used to target a state of ageing without any diseases, infirmity, or frailty conditions, with the resulting technology only addressing such health-related aspects of ageing, and ignoring other needs of older adults.

WHO, on the other hand, proposes a broader form of HA by combining its own definition of health - mentioned above - with the concept of age, and urging society to make a shift in how we think, talk and act toward age [60]. WHO defines healthy ageing 
as "the process of developing and maintaining the functional ability that enables wellbeing in older age" [58]. In this definition, functional abilities are related to each individual's intrinsic capacity, the characteristics of the environment in which they live, and the results of the interactions between these three elements. In addition, intrinsic capacity is defined as "all the mental and physical capacities that a person can draw on" [58]. With the term environment, WHO encompasses all the levels from macro, to mezzo and micro: "Environments include the home, community and broader society, and all the factors within them such as the built environment, people and their relationships, attitudes and values, health and social policies, the systems that support them and the services that they implement" [58]. Based on these, HA aims at addressing four challenges that have emerged in recent years in the discourse of ageing research [58].

The first challenge in targeting healthy ageing is "Diversity in older age" [58], which refers to the idea that there is no such thing as a typical older person, and that age is an indicator which has little to do with the mental and physical abilities of a person (for instance, an older adult might have similar capacities to a person in her twenties) $[13,17,58]$. Based on this approach, as design researchers and practitioners, we need to consider the life experiences of individual older adults, because these experiences influence their needs and desires more than our preconceived notions of their age. It is also essential for designers to recognise that "As one grows older, one grows more like oneself" [10]. Therefore, we need to find new ways to investigate this target group and overcome the urge to simply cite statistics in defining older people. This, in turn, requires us to differentiate between, and separate, the generic older adults user group into more distinguishing subgroups - as several sociological approaches have already been doing [37].

When investigating a target audience, designers need to better understand those aspects of individuals which have been influenced by their personalities and their unique environments, in addition to those elements that are genuinely related to their older age [10]. However, it is essential to remember that older adults "are not a homogeneous group" [60]. Although it should also be noted that it would be rather difficult to get such finer detailed information about ageing people from currently available data sources on older populations. For instance, demographic data on older adults are limited or non-existent for $75 \%$ of the countries worldwide [60]. Even when such data is available, they often refer to older adults as a generic group of people - for example, those older than 60-65 years [60]. These kinds of data do not consider the infinite variations that make the lives of older adults different from each other. As a consequence, relying on most existing data can actually contribute to perpetuating ageist stereotypes, if they are used without considerations given to such variations. This is because most data sources are based on the idea that "Data must be disaggregated to understand better older adults' health status, social and economic contribution, and social capital" [60].

The second challenge in targeting HA is "Health Inequities" [58], which aims to address one of the most popular topics related to age - i.e. health. Looking at health from a perspective that goes beyond the idea of physical and mental limitations or health problems is crucial to recognising the role that the environment plays in each person's life. This "environment" includes the influences that come from one's family, gender, ethnicity, and the social context in which one is born and grows up. All these 
characteristics can influence, among other things, the individual's access to health services, and discriminations to which the individual might be subjected. This means that the diversity discussed above is not random [58], and when addressing health, we need to consider the personal perspective that we develop towards ourselves, and our own health perspectives can differ from the clinical definitions of health [9]. According to a study by Bowling [9], while many older adults consider themselves healthy and successfully ageing, most biomedical classifications do not in fact categorise them as such.

The third challenge in targeting HA is "A rapidly changing world" [58]. According to WHO, macro trends such as globalisation, technological innovations, urbanisation, social migration, and changing gender norms are all elements that need to be taken into consideration when researching the HA paradigm [58]. Technological solutions are clearly of interests to those involved in the fields of $\mathrm{HCI}$ and Interaction Design, who often investigate the relationships different technologies have with the ageing process. For instance, it has been noted that this coming decade "will provide opportunities to $[\ldots]$ harness technological, scientific, medical (including new treatments) assistive technologies and digital innovation that can foster Healthy Ageing" [60].

These three challenges are influenced by the fourth underlying challenge of "Outdated and ageist stereotypes" [58]. Ageist biases and stereotypes often portray older adults as frail or dependent, and therefore, as an economic burden on society. Unfortunately, these ideas are rather pervasive and can influence society at different levels, leading to discrimination, and affecting the development of policies and opportunities aimed at older people [58]. Combating ageism is also the key to better designing for Healthy Ageing. Ageism - considered as the discrimination against people based on their age [40] - poses a barrier to research and practice of design, development, and deployment of effective interventions, and related case studies and evaluations, because ageism "influences the way problems are framed, and the question asked, and the solution offered" [60]. This is why the primary concern raised by WHO when proposing the HA framework is the urgency to change how society thinks about age. As such, in 2020 WHO launched the Decade of Healthy Ageing [60], in a commitment to help its nation members to shift their approaches towards healthy ageing and overcome ageism.

\section{$3 \quad$ Ageism}

Facing ageism is sadly a common part of the lives of most ageing people [4]. Stereotypes and prejudices about old age are so pervasive in our modern world that even older adults themselves often have such views [17, 57]. Therefore, it is not surprising that many established negative norms of an ageist society can generally be very difficult to challenge or change $[3,13]$. Nevertheless, this is something that needs to be done because ageism has a strong negative impact on older adults' mental and physical health, and can lead, for instance, to lower life expectancy, high blood pressure, reduced selfesteem, reduced risk-taking, and motivation $[42,43]$. 


\subsection{Ageism in modern society}

One of the main problems with ageism is that it is very deceptive because "it can operate without conscious awareness, control, or intention to harm." [40]. Ageism in society is a form of implicit discrimination which is influenced by emotions and thoughts beyond the control, intention, and conscious awareness of the person experiencing it [40]. Furthermore, "Implicit bias can act as a barrier to inclusion and can reinforce stereotypes and prejudices. Our subtle, unconscious judgments of others can result in behaviours that promote separateness, such as not speaking directly to an individual or not making eye contact. Implicit biases are learned behaviours that are modelled by others, including family, peers and the media" [28]. Compared to other forms of more explicit or intentional discrimination - such as racism or sexism - implicit ageism is rarely sanctioned by society. Furthermore, the presence of benevolent ageism $[14,53]$ makes it difficult to understand when it is perpetuated. A clear example of how ageist perspectives can be tolerated and perpetuated is in using ageist birthday cards [24] - e.g. showing older adults wearing diapers.

At the root of discriminatory attitudes and beliefs, we can find a number of biases and stereotypes [25]. The difference between biases and stereotypes is that the former category represents a prejudice or preconceived opinion, while the latter consists in casting one's beliefs and expectations over a person or a group of people, regardless of their actual condition [25]. Stereotypes are characterised as static entities, whose original function is to provide the people who uphold them with a sense of order that helps them make sense of their world [30].

Ageist biases can be found at different levels in our society. At a macro level, we find evidence of an ageist perspective, for example, in the beauty industry, where the term anti-ageing is widely used [40] to portray ageing as something to be avoided - or at least controlled or delayed. At a micro level, we can find an example of ageism in our language when expressing discrimination and contempt towards old age and older adults [28].

As mentioned, ageism is different from other forms of discrimination - such as racism or heterosexism - because it is often "accepted and [is] normative for most cultures" [28]. From the ageist language perspective, discriminatory remarks can easily span between two opposite poles. On the one side, we have the expression of beliefs that are intended as positive, sometimes even as compliments, and on the other side, we have verbal humiliation, which can be unintentional or intentional and result in hostility or insults [28]. Biases can be expressed explicitly, in which case, those who are expressing them are aware of their judgments and the corresponding beliefs, and evaluate them as correct to some degree [23]. Usually, these kinds of biases are not socially tolerated though and, when stated, are considered non-politically correct. Ageist stereotypes generally belong to implicit or unconscious biases, representing social stereotypes associated with certain groups of people outside of one's conscious awareness [27]. Implicit biases are very common and widespread. As such, many ageist remarks are very subtle - often passing under the radar - and can be unknowingly activated and transmitted [40]. Furthermore, implicit biases are not easy to identify, not only by the person communicating them, but also difficult to notice by the person receiving the message [28]. 


\subsection{The underlying causes of ageism}

One of the reasons behind the perpetuation of ageist beliefs is gerontophobia - i.e. the fear of ageing. Ageism and the perpetuation of stereotypes and biases can lead to people fearing their own ageing [28]. This, however, seems to be a natural thing to do for us as humans. To make sense of the world in which we live, we use social categorisations, identifying people with similar characteristics to ourselves "as part of our group (ingroup) or as different from those who constitute our group (outgroup)" [28]. Therefore, ageism can be externalised when the ingroup perpetuates it towards the outgroup, or internalised when it is inflicted by the ingroup upon itself [28].

In the case of ageism, there is also a paradox which we need to take into consideration that constitutes a unique characteristic of this form of discrimination. Jönson [32], underlines how, in the case of young people discriminating towards older adults, the perpetrators themselves will become part of the victimised group at some point in time in the future. In other words, the ingroup eventually becomes the outgroup. Realising that we are part of the outgroup can have drastic consequences in terms of our thinking and behaviour towards the outgroup. Pickering [47] describes the experience of us realising that we are part of an outgroup, by noting that "[...] imprisoned in an identity that harms you. You are both silenced and spoken for. You are seen but not recognised. You are defined but denied an identity you can call your own. Your identity is split, broken, dispersed into its adjected images, its alienated representations" [47]. This theory relies on the fact that we usually prefer our own ingroup members and discriminate against the outgroup members [28]. Bogardus [56] calls the distinction between one's own identity and other groups' identities as social distance - a mechanism that can be used to measure one's prejudices.

To better understand stereotypes, social psychologists have proposed the stereotype content model [26], according to which stereotypes have two dimensions: warmth and competence. The first dimension is used to judge strangers' intentions towards us - i.e., whether they intend to help or harm us - and the second dimension is used to judge their competence in carrying out their intentions. Social groups that do not compete with the ingroup are perceived as "warm" and those characterised by a lower status for instance, due to economic or cultural reasons - are perceived as "incompetent" [26].

In ageism, stereotypes manifest themselves from a young age, with even children and teenagers expressing them [54]. According to Levy [41], ageist stereotypes operate from the society to individuals, and, during their lifespans, within the individuals themselves. This idea is best examined through the age stereotype embodiment theory, which shows how stereotypes are assimilated through the environment, including popular culture, everyday interactions, and social norms [41]. It is evident that the society we live in plays a crucial role in creating, perpetuating, and normalising ageist stereotypes. The media is full of examples in which older adults are made fun of - e.g. commercials showing older adults as unable to use technology, or engaging in sexual behaviour [19] [28]. This type of continuous exposure to ageist stereotypes from a young age turns them into an effective part of our mental schema, both implicitly and explic- 
itly, and thus creating internalised ageism [40]. This form of discrimination is then perpetuated by the ingroup - i.e. older adults themselves - against other members of their own ingroup. Examples of this can be found in people who do not want to be associated with peers of their age or resort to extreme measures - e.g. plastic surgery - to look like someone in a younger age group [28].

Furthermore, according to the attachment theory and its internal working model concept, mental representations of one's self, and fellow human beings, play an essential role in shaping our social relations, feelings, and thoughts [8]. Based on this theory, the way we construct our age identity is strongly related to social processes in which we engage with others - such as talking - and the quality of such interactions [61]. Furthermore, it is worth noting that age identity is not something static. As such, we can decide to use multiple stereotypes associated with age to describe our age identity and experience, and we can adopt age norms that are associated with different ages - such as when an older adult identifies herself with a different age group when describing her personality [38].

\subsection{The role of language in addressing ageism}

WHO emphasises that the above mentioned challenges facing the HA framework can only be addressed through transdisciplinary approaches and a multiplicity of methods and perspectives. It further proposes that a research network should be established to create a common ground between researchers from different fields [60]. We believe that formulating a common ground is the much needed first step in creating dialogue, and developing "an approach that crosses traditional disciplinary borders and critically extends a disease-focused methodology" [34].

This radical change in perspective can be achieved by starting from the language we use to discuss age. "Language is the basis through which we communicate with each other. Through language, we share our thoughts, ideas, and emotions" [28]. While the language we use, and the way we think are closely related, the quest to understand if and how language influences the thinking process - and vice versa - is one of the oldest topics debated in research [62]. Here, we adopt the assumption proposed by Zlatev and Blomberg [62] that there is a direct relationship between language and thought, and it is, in fact, likely that language influences thoughts. We propose that if we consciously repeat the process of adopting a specific lexicon when referring to ageing and older people, we are then more likely to modify our way of thinking about ageing, or at least, critically question our existing false assumptions regarding ageing. This, in turn, will pave the way to a more precise and inclusive language on age [2], particularly in transdisciplinary research and practice settings.

Furthermore, it is understood that "Long-standing cultural practice can exert a powerful influence over even the most conscientious writer" [2]. Therefore, it is crucial that as design researchers and practitioners we should first recognise and identify possible ageist biases and stereotypes in our discourse, and modify how we talk and write about ageing and older adults in the design context.

In our quest to become more conscious of implicit ageist biases and stereotypes in our thinking and language, we should also be mindful of the pitfalls of becoming, what 
we refer to here as, false friends in our discourses regarding ageing. The term "false friends" is popular amongst the linguists who use it to identify words that look and sound similar in two different languages but differ significantly in their meanings. In our context, false friends refer to apparently innocuous words in discourse about ageing which reveal underlying implicit ageist attitudes and stereotypes. As such, false friends indicate the best of intentions from the person using a terminology, word, or phrase which is ultimately faulty in expressing the real intended meaning.

\section{Common Ageist Biases and Stereotypes}

We believe that because of the implicit nature of ageist biases and stereotypes in our modern societies, it is necessary to make conscious effort in better identifying them before we can attempt to eliminate them. This is also due to the fact that "people are often unable to identify the bias by typical means of introspection" [28]. In the following sections we have divided the most common ageist biases and stereotypes we have identified into three main categories, and provide some examples to describe them.

\subsection{Generalisations and assumptions about ageing people}

One of the main steps in most design research or practice projects is to identify and frame a question to be addressed. As design researchers or practitioners, we often follow our intuition that may or may not guide us towards a possible knowledge gap in need of investigation. However, when dealing with an ageing population, we have to be mindful that this "intuition" may have been strongly influenced by ideas that might be true only for a segment of an ageing population, but not necessarily for the entire group [5]. In fact, in worse case scenarios, our intuition might even be based on ageist assumptions and judgments [28], which might be far from actual reality.

Most ageist assumptions and judgments are similar to what Bell calls "stock stories" [6], in her case when dealing with the issue of racism. She defines these as stories or narratives which are widespread in our society, but are based on biased ideas that seem to make sense by being strongly grounded in so-called "common sense". In the case of racism, these are stories that narrate stereotypes, which are repeated when talking about certain topics, and are presented as justification for why racism is the way it is, and is not going to change. In the case of ageism, these stories are usually backed up by statistical data or facts that are found in governmental laws or institutional regulations even though ageism is so pervasive that it influences not only individuals but also institutions and policies $[9,60]$. The mechanism behind the creation of such stories is best illustrated by Krekula [38], who presents the case of retirement in Sweden as an example of how the law - that proposes 65 as the age of retirement - can be used as a proof that people over the age of 65 are of less value to society than those who are younger and are perceived as being still active in some form of paid employment.

Therefore, it is clear that one should stop perpetuating stock stories of ageing and avoid defining the target audience of design solutions solely based on the age criteria. This is in fact a common form of being false friends, influenced by demographic fore- 
casts and classifications of ageing populations based on measurements which were perhaps relevant in the past but are no longer valid. In following the HA framework, it is important to find other means of classification of the target audience when designing for ageing people. For instance, in addition to age, it is important to consider the lived experiences of the target audience, their environments, and their functional and intrinsic capabilities [60].

The list below provides a few examples, to highlight some, but clearly not all, the stereotypes which can be included in this category of "stock stories".

Longevity is hereditary. This stereotype describes the misconception that we will die at similar age to our parents, or will suffer from all the same health-related issues as them. If one comes from a family with perceived longevity traits, this misconception can create a "moral hazard" and a false sense of immunity. In reality, longevity is strongly linked to our lifestyle, and our quality of life is directly influenced by the lifestyle choices we make during our lifespan and the environments in which we live [13]. For example, Type 2 Diabetes is more common in Western countries due to a low-fibre diet and less physical activities [13] than any specific genetic population characteristics.

Homogeneity of age: This relates to the idea that all people who are in the $65+$ demographic category share similar characteristics. Common stereotypes associated with older adults depict a group of people who are sexless, boring, and all the same [52]. In reality, ageing is very subjective [3]. The habits and the life experiences we have in our lives make us all age differently. For instance, if we look at a group of 70-year-olds carefully, we will soon realise how different they look compared to each other [3].

Loneliness: While this may seem like something to be associated with social isolation, in reality, there are many other dimensions to loneliness. Loneliness and social isolation can occur simultaneously, but there are also other factors that can cause loneliness.

Misery and loneliness is one of the variations of this stereotype, and relates to the assumption that older adults are usually not only lonely but also sad. A common stereotype is to imagine older adults as "sad, depressed, lonely, grouchy" [52]. According to Carstensen [13], there are actual facts proving this to be an ageist myth: 1) mental health generally improves with age - except for people living with dementia, 2) OA better manage their negative emotions, 3) OA have a better socio-emotional selectivity in deciding who to spend their time with, and 4) OA report higher levels of happiness.

Well-off older folks: This is about the idea of an elite group of older adults who spend all their time in constant vacation [19]. This not only creates false expectations in some older adults themselves, but also causes hate and discrimination by younger people who might be feeling jealousy towards the so-called richer older adults.

You can't learn new things in old age: This is also known as "you can't teach an old dog new tricks". It is based on the idea that the more we age, the more difficult it becomes for us to learn new things. This stereotype depicts older adults as "unable to learn 
or change" [52]. While this stereotype is very pervasive, we would immediately notice how untrue it is if we only focused on its real meaning. In a recent article in The New Yorker, Talbot reviewed a series of books that talk about learning new skills in old age [51]. This demonstrates that it is not only possible to learn as we age, but the topic is so relevant that there is an entire range of popular literature emerging in this area.

\subsection{Considering ageing people as an estranged group of people}

This category of stereotypes and biases is strongly influenced by the theory of ingroup/outgroup [28], as discussed earlier. The idea that older adults are a very distinct group of people - different from the rest of us - is false, due to the fact that we are all ageing and, if we are lucky, one day we will be able to consider ourselves as part of the older adult population [32]. Ageing is not something that happens after a certain age, but rather, it is a process that starts from the very moment we are born [3]. Framing older adults as different from "our" ingroup of "younger" people can lead to the creation and perpetuation of ageist stereotypes. Unfortunately, this is another difficult bias to tackle, as it is formed and reinforced by society during our entire lifespan [54]. A nonexhaustive list of stereotypes that fall under this category includes the following.

Intergenerational conflict: This is tied to the idea that "the old benefit at the expense of the young" [3]. The media is often presenting an intergenerational conflict in which younger adults are resentful towards an elite of older adults who grew up during an economic boom and had an easier and more wealthy life - e.g. the idea of baby boomers versus millennials. In reality, according to McArthur Foundation, there is no clear evidence of such a conflict [3]. When asked, young people are not resentful towards the older adults of their own family or their community. The resentfulness is towards an abstract category called "elderly" or "boomers", the use of which dehumanises older adults as people. The real issue that we need to talk about is the fact that socioeconomic differences become even greater in old age. For older adults, there is a huge difference between who is wealthy and educated - e.g. those who live without frailty - and who are poor and struggling - e.g. those who often end up with disabilities and die earlier than expected [13] p.40, [3] p.30. When discussing the ageing population, the most pressing issue is not the differences between the generations, but the socioeconomic differences within the same age group.

Older adults are a burden to society: This stereotype perpetuates the idea that older adults consume the natural and economic resources of states and governments $[3,13]$. It is based on the ideas that if people live longer, then in the future there will not be enough resources to support everyone, and that older people are the cause of overpopulation. The reality is that in those regions of the world where there is higher longevity, the population size has either stabilised or, in fact, declining - as is the case in many parts of Europe, for example.

Care in old age: This is based on the idea that when people grow old, they get sick and are in need of care more than when they were young. The truth is that the medical 
expenses are higher for everyone during the period before they die - be it at 18 or 81 [3]. The real question here is what we consider the "value of life", and the fact that we might value the life of an 18-year-old more than that of an 81-year-old - which itself is an ageist opinion endorsed by society.

Retirement: There are many stereotypes connected with retirement. The most common stereotype is based on the idea that there is somehow a direct financial link between people who are working and those who are retired. This idea is very popular in countries with a "pay as you go" pension model. In these countries, the media usually presents the link between the workforce and the pensioners, suggesting that the former is directly supporting the latter by "paying" for them. This concept is best summarised by the oldage dependency ratio, which calculates how many people aged 15-64 in a country are active and how many people over 65 are retired. However, most such calculations ignore the reality that many retired people are contributing to the economy and society in different ways - especially through informal economy, voluntary work, being caregivers, and staying socially active, not to mention that in a lot of instances pensioners offer support to their adult children and their families [60].

Retire early to create space: Another popular stereotype associated with retirement is that older adults should retire early to provide employment opportunities for younger people. The reality is that if all the older adults retired early then, in many cases, there would be a shortage of skilled labour [13], and some companies might even go bankrupt - for example, consider the case of a German car manufacturer fighting to keep its ageing engineers with the right knowhow employed [17]. Furthermore, as mentioned above, the related notion of "well-off older folks" who can retire early influences older adults themselves greatly with other stereotypes such as "work hard, retire harder". Such notions perpetuate the belief that if people have worked all their lives, then they should be able to retire and go "on holiday" for the rest of their lives. The reality is that the idea of "holiday" retirement may have made sense when people had just ten years of life expectancy after their retirement at the age of 65 [13] p.30. These days, however, the idea that after retirement one should not work does not make sense any longer. "You cannot think to work for 40 years and have enough money to support yourself for the next 40" [12]. In most developed countries, there is also a need for pension reforms and a societal change in how we view saving for retirement and our lives after retirement.

"Just kill me": This stereotype refers to the thought that someone might have when seeing an older adult who lives with debilitating or terminal physical or cognitive frailty. It is based on the idea that the life of such a person is not worth living. While this is largely a personal and moral issue, it is difficult to know how we might react if we were in a similar condition ourselves as individuals. More importantly, we cannot place a value on the life of such older adults, because that is ultimately ageist, insensitive, and offensive [19]. 


\subsection{Certain actions should not be done by ageing people}

Some stereotypes are strongly influenced by the assumption that certain actions can be performed only at a certain age [28]. Krekula [38] presents the concept of "age coding" to explain how these assumptions are created, reinforced and normalised by society. These norms are based on the assumption that certain actions and behaviour are more appropriate at a certain age, and, as a consequence, individuals who feel that they belong to that age group choose to behave in the expected way to be accepted by society [38]. Krekula presents the case of a woman in her 80 s, who states that she is not having intimate relationships with her partner because of her age. Such stereotypes are reinforced by phrases such as "you look old/young for your age" - which in this case is not a comment on our individual life but on the expectation of what our age means to the person saying it, or what that person imagines our age to represent [3].

The influence of ageist biases on our language can result in microaggressions towards older adults. Microaggressions are, for example, "[...] brief and everyday slights, insults, indignities and denigrating messages sent to people of colour by well-intentioned white people who are unaware of the hidden messages being communicated" [22]. This is an important point to remember, becasue often things we mean as compliments can, in fact, be harmful. A non-exhaustive list of stereotypes that fall under this category are discussed below.

I do/don't feel my age, or you don't look your age: This idea is perpetuated by what our society thinks we should or should not do at a certain age. This feeling can lead to internalisation of ageism when we do not feel we should be part of our ingroup because we behave differently [28]. Perhaps we should consider the fact that if many older people claim to be "younger" or "feeling young" because of what they are doing, then what they are doing should really be considered normal for their age [3].

Older adults as not being capable: This stereotype encompasses all the attitudes that are infantilising or patronising older adults. It is related to the tone and usage of specific words that strip older adults of their expertise, independence and abilities $[19,28]$.

Deficit model of ageing: Treating older adults as a category of people different from others is referred to as the "deficit model of ageing" [5]. It focuses the attention on the possible physical, mental and psychological fragility of the target audience. This approach is mainly present in clinical settings, and it influences other fields that rely on health definitions based on this idea. While this perspective might be valid from a clinical perspective, when applying the HA framework however, we also need to consider other factors, such as the subjective perception of age which can be different from medical classifications of age [9]. This perspective can be easily avoided if we imagine ourselves at a given older age - when we do so we rarely imagine living with deficits, on the contrary, we think that our lives will not be much different from what they are now [17]. A non-exhaustive list of words and stereotypes that fall under the deficit model of age are:

- "Feisty, spry, sweet, little, feeble, eccentric, senile, grandmotherly" [19] 
- (Pronoun) is XX young!! [19]

- Inability to use new technologies, including computers and the Internet [19]

- Second childhood stereotype [19]

- Poor health, ill, disabled [52]

- Lack of mental sharpness failed memory, senile [52]

- Lack of vitality, loss of vigour, inevitable decline [52]

\section{$5 \quad$ Addressing Ageism in Design Research Discourse}

As discussed, ageist biases, stereotypes, and beliefs are so implicit in discourse that often design practitioners and researchers - even with the best of intentions - fail to recognise elements of ageism in their design discourse. When it comes to academic research in design-related areas, more than might be expected, even the reviewers of any resulting publications fail to identify such ageist language in their reviews.

In this section we provide some guidelines which we believe will assist researchers and practitioners in avoiding such biases and stereotypes in their design discourse. We have chosen some examples from published literature to highlight the implicit nature of such pitfalls. It is important to underline that in selecting our examples, we refer to studies in which researchers expressed high sensitivity toward the age-related topics presented in their publication. We did this to demonstrate that ageism is truly implicit, and as such, it can impact and influence even those with the best of intentions.

One of the most common false friends that we found under the category of generalisations and assumptions about ageing people is the representation of older adults as a homogenous group with a natural decline in cognitive and physical frailty issues [15, 49], or the selection of the target audience using a demographic identification of older adults as $65+$, resulting in groups of participants where numerous and very different cohorts are investigated as a whole unique group [39, 48].

For the category of considering ageing people as an estranged group of people, we found that the most common false friends made the false assumption that all older adults are a group of people with unique characteristics $[18,35,36]$, and perpetuated the ingroup/outgroup dynamic between the researchers and their older age participants [15, 29, 30].

For the category of certain actions should not be done by ageing people, some of the false friends we found included the use of a paternalistic tone, or surprise when older adults performed behaviours that are considered perfectly normal for other age groups [18]. Some of them also presented the idea that with age there is an inevitable decline that occurs, and that certain handicaps and impairments emerge $[1,15,29,30$, $36,46]$. As mentioned earlier, while such assumptions are true in some cases, they are by no means universal.

In what follows, we present a list of practical guidelines on the use of appropriate language in discourse regarding ageing and older adults. Language is strongly connected with society, and it is in continuous development $[2,31]$. Therefore, this list is meant to be only a starting point, expected to be expanded and improved in the future. 


\subsection{Using a person-first language}

To avoid ageist discrimination, it is important to keep in mind that the most important element when talking about ageing people or older adults is their individual "persons" and not their age [2]. We can start by asking ourselves questions such as: Is the person's age meaningful in our research? If yes, why? Is the use of age triggered by ageist stereotypes and biases? [12] These questions can be a good first step in understanding if our intentions are well-motivated or formed by implicit ageist biases. If we realise that age is not such an important element, then we can proceed to refocus our research on what is important from ageing perspective. We should always consider that there is a distinction between age and problem - age alone cannot be the problem [31].

Avoiding a patronising tone: When talking about older adults and ageing people, often the problem is the tone used that can become patronising [12]. It is important to avoid the idea that some activities that are normal for a young cohort are a deviation to the norm for older adults. For instance, rather that describing an "active" 80-year-old person with surprise, if it is relevant to the study, it might be more useful to describe the activities that the 80-year-old person is pursuing [31,33]. Similarly it is important to avoid using words such as feisty, spry, sweet, little, feeble, eccentric, senile, grandmotherly [33] when referring to study participants - just as using such terms with younger participants would naturally be considered, for instance, sexist.

Talking about cognitive or physical frailties: In discussing such important issues, it is crucial to consider the person first. Many studies focus on how to overcome situations where people live with dementia or physical impairments. Following a personcentred approach in such studies requires these considerations:

- Avoiding phrases such as "xxx suffer from xxx" or "xxx is affected by $x x^{\prime}$ ", instead saying "xxx lives with $x x x "$ [12]. This approach puts the accent on the person and keeps the human side at the centre of the conversation, thus avoiding the mistake of using a disease, a disability, or an impairment as the centre of the identity [2].

- Avoiding words such as demented or senile, and instead using phrases such as living with cognitive impairment $[12,19]$.

- Avoiding words such as dependent, incapable, needy, and instead using terms such as receiving assistance, needing ... [12,31].

- Avoiding words that over-medicalise the participants or the target audience [12,31].

- Considering the subjective self-perception of the participants. Even if there are statistics that might indicate health decline after a certain threshold, this does not mean that the people who are part of that demographic feel impaired or are living with bad health - on the contrary, their self-perception might be of good health due to their resilience $[9,31]$.

Talking about retirement houses and care homes: When talking about retirement houses and care homes, it is important to avoid reinforcing the stereotype of focusing on places or facilities, and instead focus on communities of people. In doing so, we put 
people first and reinforce the idea that these are communities where people live [12]. For instance, people who live in a retirement house can have fulfilling and often happy lives, rich in relationships, friendships and everyday activities. We must recognise this by using words that enhance this idea. Following this approach would require:

- Avoiding the use of terms such as facility, old folks home, convalescent home, institution, and instead preferring to the community, senior living, assisted living [12].

- Avoiding the use words such as units or beds, and instead use terms such as apartment, residence, home [12].

- Avoiding the term patients, and instead using the term residents $[12,19]$. It is important to keep in mind that the terminology used in a medical setting might not be appropriate in the field of design or academic research [31].

\subsection{Using a positive language}

To change how we think about ageing, we need to start focusing on words that describe ageing in a positive light, and as a natural fulfilling process. To do so requires the use of words that are characterised by a positive connotation [12], and avoiding the use of a resigned tone depicting ageing as an obstacle to overcome [2] or to surrender to.

Highlighting capabilities: Instead of using words that focus on the loss of capacity of self - e.g. frail, declining, deteriorating, fragile, invisible, diminished, gone - it is important to use words that highlight capabilities - e.g. engaged, adventurous, thriving, independent, capable, wellness [12].

Focusing on positive stereotypes, if it is not possible to think of anything better. When starting from the idea of ageing firmly grounded on a deficit model of ageing [5] it can be challenging to radically switch perspective. In such cases, the very first step might be to focus on the positive stereotypes associated with ageing [12]. However, this should be considered as just a temporary solution, since positive stereotypes can also easily result in paternalism towards older adults [14]. Nevertheless, it has been proved that positive or benevolent stereotypes can at least have immediate positive effects on the lives of older adults [40]. This approach requires the following:

- "Make[ing] sure that your language conveys that ageing is a normal part of the human experience and is separate from disease and disorder" [2].

- Avoiding the use words that devaluate - e.g. a burden or drain on the system - and instead focusing on words that value the older adults' experience - e.g. their wisdom, experience, contribution, guidance [12].

- Avoiding the use of words that might highlight a negative character or attitude e.g. difficult, stubborn, non-compliant, cranky - and instead using words that highlight the sense of self-worth - e.g. empowered, enabled, fulfilled, self-assured, confident, acceptance [12]. 


\subsection{Precision}

It is important to be precise and accurately depict the communities we are investigating; we need to avoid assumptions based on stereotypes and generalisations $[2,12]$.

When in doubt, ask? When sure, ask anyway! We should always be asking our participants what they want to be called, do they prefer the term older adults, older persons, or just for us to use their names [12, 33]? What kind of community do they live in? When a participant suggests using a doubtful term, it is better not to use it and use the most appropriate term instead [2].

\subsection{Avoiding ageist words and concepts}

There are specific ageist concepts that are elicited by specific ageist words. The list we report below is in no way exhaustive; it is a changing and transforming list influenced by how society evolves and language transforms [31]. Some terms that might not be tinted today might be considered not acceptable tomorrow.

Avoiding the use of 'old' as negative or 'young' as positive. Old as negative: The word old is used to indicate an undesirable state. This can be an opinion that is expressed by a third party (researcher, media, caregiver...) or expressed by the older adult herself [28]. I'm feeling old is an example of the word 'old' used as a synonymous of feeling bad, with no vitality [3]. Young as positive: It can be used independently from 'old as negative', but they are strongly related. Is the expression of the assumption that being, acting, or looking younger is preferable to being, acting and looking older [28]. It's essential to understand what we mean with the word old or young and find better terminology to express our thoughts.

Words such as old or young are adjectives describing a person's state; they shouldn't indicate an emotional state [3]. Removing the emotional value from the word, we see how the power of the stigma diminishes. When words such as old or fat are spoiled of their original meanings, they can represent ideas that are extremely harmful and discriminatory; by adding biases and stigmas to the adjective old and the noun fat, we transition them into harmful emotions [3].

Chronological age. The first question we should ask ourselves when talking about older adults is "is age truly relevant here?". This can be quite difficult to determine due to the pervasiveness of implicit ageism. One way could be to try to substitute age with race; race is less normed than age, and it is immediately clear when adding this detail can be considered redundant or, worst, racist [33].

Consider that a cohort is made of people that share the same year of birth; this means that their lives can have been influenced by similar world events (such as wars, songs, etc.) but that these facts might have affected everyone in different ways [31]. When describing chronological age, avoid adjectives such as old, elderly, aged, ancient; instead use words such as older, elder, ageing, mature [12]. Avoid nouns such as old person, or senior citizen, prefer older adult, elder, older people, older person, older 
individual, persons 65 years and older, and the older population [2, 12]. Always question if it is crucial to refer to years or if it might be better to refer to life stages [31].

Avoiding the word senior [19]. This an example of a word that has been largely influenced by the development of society. If it was fine to use the word senior to describe a person in 2007 [33], now it is sometimes possible to use it just when referring to nonhuman entities, such as a senior house or a company that provide senior housing and services; the word should be entirely avoided when referring to people as it is considered highly offensive $[2,12]$.

Avoiding the word elderly. Elderly is, arguably, the most ageist word we can use when talking about older adults. It is associated with an incredible amount of negative stereotypes (such as frail, old, highly handicapped and disabled) and it's a term that fuels the stigma on older adults $[2,33]$. Elderly reinforces the idea of a homogenous group characterised by fragility and decline; for these reasons, this word, should be avoided completely [33].

Boomer or baby boomer. The terms boomer and baby boomer refer to a specific cohort; they should be used just with this meaning and intention [2,33]. In recent years the terms have been associated more and more with negative stereotypes on old age. The terms have been used when discussing intergenerational conflicts describing a younger generation as millennials and an older generation as boomer [44]. "Ok, boomer!" is an example of how the word can be used as a synonymous of someone who is out-of-touch, who has outdated or conservative beliefs, and is delaying the progress on societal matters, economic inequalities, or environmental issues [44].

Middle-age or midlife. As for the terms boomer or a baby boomer, also middle-age and midlife should be used to identify a specific moment during the lifespan, but they should not be used to identify people [33]. Furthermore, when using terms such as middle-age or midlife, it is important to understand what we are trying to say: this is a concept that varied during time as life expectancy has been rising [33]. The International Council on Active Ageing [31] suggest using the following categories when in need of specification: Middle Age 45-64; Young Old 65-74; Middle Old 75-84; Old Old 85-99; Oldest Old 100 years or more. When talking about individuals, avoid using the word middle-aged, prefer people in middle age [31].

Concepts and words can have political implications. When discussing topics such as care costs or health expenses, it is important to be aware that using words such as the burden of population ageing, or this plan will save $x x$ on health spending, imply the belief that one group of society is more valuable than another [33]. These ideas are not neutral; they are expressions of particular political stances. 
Antiaging. The term is used in the beauty industry and marketing, and it is a clear example of how political correctness is not offered to older adults, as it is with many other marginalised groups [31, 40]. Avoid using words such as anti-ageing, aged or phrases such as they look good for their age, despite their age; even older adults can $x x x$, are active even at their age [31].

Senior moment. The concept of the senior moment become very popular in the US and become relatively normalised [7]. It is a moment when an older adult might forget the name of a person, or experience some issues with memory; it is used in a derogative tone. The same stigma is not applied to younger people who may experience the same temporary memory loss, for example, while talking.

\section{Conclusions}

This article examined the paradigm of Healthy Ageing as proposed by WHO, which calls to radically change the way we talk, think, and act about age. To achieve such change, we proposed modifying the lexicon we use to discuss age in a more inclusive and bias-free way. We investigated what ageism is and how it is perpetuated in our society. We presented guidelines on identifying ageist stereotypes and biases: we called these false friends to underline their subtle nature. We propose practical guidelines on how to modify the lexicon surrounding age.

The environment strongly influences ageist biases and stereotypes; future works might focus on how specific research fields influence our idea of ageing. We strongly believe that adopting these guidelines will help overcome ageist biases that might influence our studies and change the way we approach ageing.

\section{Acknowledgments}

We would like to thank Professor Andrea Gaggioli for providing valuable feedback during the writing of this paper.

\section{References}

1. Alexandrakis D, Chorianopoulos K, Tselios N (2019) Insights on Older Adults' Attitudes and Behavior Through the Participatory Design of an Online Storytelling Platform. In: INTERACT 2019. pp 465-474

2. American Psychological Association (2020) Publication Manual of the American Psychological Association (7th ed.), American Psychological Association (APA)

3. Applewhite A (2016) This chair rocks: a manifesto against ageism. Perfect Paperback

4. Ayalon L, Tesch-Römer C (2018) Contemporary Perspectives on Ageism. Springer Open

5. Bangen KJ, Meeks TW, Jeste D V. (2013) Defining and assessing wisdom: A review of the literature. Am J Geriatr Psychiatry 21:1254-1266. doi: 10.1016/j.jagp.2012.11.020 
6. Bell LA (2010) Storytelling for Social Justice. Connecting Narrative and the Arts in Antiracist Teaching. Routledge, New York and London

7. Bonnesen JL, Burgess EO (2004) Senior moments: The acceptability of an ageist phrase. J Aging Stud 18:123-142. doi: 10.1016/j.jaging.2004.01.008

8. Bowlby J (1979) The making and breaking of Affectional Bonds. Travistock Publications Limited, London and New York

9. Bowling ANN (2007) Aspirations for Older Age in the 21st Century: What is Successful Aging? Int Jou Aging Hum Dev 64:263-297

10. Brody EM (2010) On being very, very old: an insider's perspective. Gerontologist 50:2-10. doi: 10.1093/geront/gnp143

11. Burns L, Masoodian M (2018) Storytelling: A Medium for Co-design of Health and WellBeing Services for Seniors. In: ICEC 2018, LNCS 11112. Springer International Publishing, pp 349-354

12. California Assisted Living Association (2019) Elevate Aging Through Language: a Usage and Style Guide

13. Carstensen LL (2011) A long bright future : happiness, health, and financial security in an age of increased longevity. Public Affairs

14. Cary LA, Chasteen AL, Remedios J (2017) The ambivalent ageism scale: Developing and validating a scale to measure benevolent and hostile ageism. Gerontologist 57:e27-e36. doi: 10.1093/geront/gnw118

15. Cogerino C, Rosso G, Bosi I, Frisiello A, Bazzani M (2017) Multi-modal input devices for active and healthy ageing. 25th Int Conf Software, Telecommun Comput Networks, SoftCOM 2017. doi: 10.23919/SOFTCOM.2017.8115562

16. Comincioli E, Masoodian M (2019) A Storytelling-based Approach to Designing for the Needs of Ageing People. In: Adjunct Proceeding, The 17th IFIP TC.13 International Conference on Human-Computer Interaction - INTERACT 2019

17. Coughlin JF (2017) The longevity economy: unlocking the world's fastest-growing, most misunderstood market. PublicAffairs, New York

18. D'Haeseleer I, Gerling K, Schreurs D, Vanrumste B, Abeele V Vanden (2019) Ageing is not a disease: Pitfalls for the acceptance of self-management health systems supporting healthy ageing. ASSETS 2019 - 21st Int ACM SIGACCESS Conf Comput Access 286-298. doi: $10.1145 / 3308561.3353794$

19. Dahmen NS, Cozma R (2009) Media Takes: On Aging. Styleguide for Journalism, Entertainment and Advertising. Internation Longevity Center - USA | Aging Services of California

20. Dankl K (2013) Style, strategy and temporality: How to write an inclusive design brief? Des J 16:159-174. doi: 10.2752/175630613X13584367984866

21. Dankl K (2017) Design age: Towards a participatory transformation of images of ageing. Des Stud 48:30-42. doi: 10.1016/j.destud.2016.10.004

22. Derald Wing Sue (2010) Racial Microaggressions in Everyday Life: Is Subtle Bias Harmless? In: Psychol. Today. https://www.psychologytoday.com/us/blog/microaggressions-ineveryday-life/201010/racial-microaggressions-in-everyday-life

23. Devine PG (1989) Stereotypes and prejudice: Their automatic and controlled components. J Pers Soc Psychol 56:5-18. doi: 10.1037//0022-3514.56.1.5

24. Ellis SR, Morrison TG (2005) Stereotypes of ageing: Messages promoted by age-specific paper birthday cards available in Canada. Int J Aging Hum Dev 61:57-73. doi: 


\subsection{0/ULUU-UN83-8W18-EP70}

25. Fiske ST (2014) Social Beings. Core Motives in Social Psychology, Third Edit. Wiley

26. Fiske ST, Cuddy AJC, Glick P, Xu J (2002) A model of (often mixed) stereotype content: Competence and warmth respectively follow from perceived status and competition. J Pers Soc Psychol 82:878-902. doi: 10.1037/0022-3514.82.6.878

27. Fiske ST, Taylor SE (2017) Social Cognition: from Brain to Culture, Third Edit. Sage

28. Gendron TL, Welleford EA, Inker J, White JT (2016) The language of ageism: Why we need to use words carefully. Gerontologist 56:997-1006. doi: 10.1093/geront/gnv066

29. Giakoumis D, Segkouli S, Votis K, Paliokas I, Altsitsiadis E, Tzovaras D (2019) Smart, personalized and adaptive ICT solutions for active, healthy and productive ageing with enhanced workability. ACM Int Conf Proceeding Ser 442-447. doi: 10.1145/3316782.3322767

30. Helbostad JL, Vereijken B, Becker C, Todd C, Taraldsen K, Pijnappels M, Aminian K, Mellone S (2017) Mobile health applications to promote active and healthy ageing. Sensors (Switzerland) 17:1-13. doi: 10.3390/s17030622

31. ICAA (2011) ICAA's Guidelines for effective communication with older adults. International Council on Active Aging

32. Jönson H (2013) We will be different! Ageism and the temporal construction of old age. Gerontologist 53:198-204. doi: 10.1093/geront/gns066

33. Kleymann P (2007) Words to Age by: a brief Glossary and Tips on Usage. Age Beat. Newsl. Journalists Exch. Aging

34. Kliegel M, Iwarsson S, Wahrendorf M, Minicuci N, Aartsen MJ (2020) The European Journal of Ageing at the beginning of the Decade of Healthy Ageing. Eur J Ageing 17:1-2. doi: 10.1007/s10433-020-00557-8

35. Knowles B, Rogers Y, Waycott J, Hanson VL, Piper AM, Davies N (2019) HCI and aging: Beyond accessibility. Conf Hum Factors Comput Syst - Proc 1-8. doi: 10.1145/3290607.3299025

36. Kolasinska A, Quadrio G, Gaggi O, Palazzi CE (2018) Technology and aging: Users' preferences in wearable sensor networks. ACM Int Conf Proceeding Ser 153-158. doi: $10.1145 / 3284869.3284884$

37. Komp K, Aartsen M (2013) Old Age in Europe. A Textbook of Gerontology. Springer

38. Krekula C (2009) Age coding - On age-based practices of distinction. Int J Ageing Later Life 4:7-31. doi: 10.3384/ijal.1652-8670.09427

39. Lee HR, Riek LD (2018) Reframing Assistive Robots to Promote Successful Aging. ACM Trans Human-Robot Interact 7:1-23. doi: doi.org/10.1145/3203303

40. Levy B, Banaji MR (2002) Implicit Agesim. In: Ageism. Stereotyping and Prejudice against Older Persons. MIT Press

41. Levy BR (2009) Stereotype Embodiment: A Psychosocial Approach to Aging. Curr Dir Psychol Sci 18:332-336

42. Levy BR, Hausdorff JM, Hencke R, Wei JY (2000) Reducing Cardiovascular Stress With Positive Self-Stereotypes of Aging. J Gerontol Psychol Sci 55B:205-213

43. Levy BR, Slade MD, Kunkel SR, Kasl S V (2002) Longevity increased by positive selfperceptions of aging. J Pers Soc Psychol 83:261-70. doi: 10.1037//0022-3514.83.2.261

44. Meisner BA (2020) Are You OK, Boomer? Intensification of Ageism and Intergenerational Tensions on Social Media Amid COVID-19. Leis Sci 0:1-6. doi: $10.1080 / 01490400.2020 .1773983$ 
45. Michel J-P, Leonardi M, Martin M, Prina M (2021) WHO's report for the decade of healthy ageing 2021-30 sets the stage for globally comparable data on healthy ageing. Lancet Heal Longev 2:e121-e122. doi: 10.1016/s2666-7568(21)00002-7

46. Ordoñez Medina OE, Cornejo R, Manzo A, Alarcón A, Gaxiola L, Martínez F, Duque L, Ornelas M (2019) Design implications for exergames with moderate activity to improve inter-joint angle for older adults. ACM Int Conf Proceeding Ser 1-8. doi: $10.1145 / 3358961.3358964$

47. Pickering M (2001) Stereotyping: The Politics of Representation. Palgrave

48. Rodríguez I, Karyda M, Lucero A, Herskovic V (2019) Aestimo: A Tangible Kit to Evaluate Older Adults' User Experience. Lect Notes Comput Sci (including Subser Lect Notes Artif Intell Lect Notes Bioinformatics) 11746 LNCS:13-32. doi: 10.1007/978-3-030-29381-9_2

49. Sarcar S, Munteanu C, Jokinen J, Oulasvirta A, Charness N, Dunlop M, Ren X (2018) Designing interactions for the ageing populations. Conf Hum Factors Comput Syst - Proc 2018April:1-5. doi: 10.1145/3170427.3170607

50. Sholl J, Rattan SIS (2020) Explaining Health Across the Sciences. Heal Ageing Longev 12:368. doi: https://doi.org/10.1007/978-3-030-52663-4

51. Talbot M (2021) Why It's Not Too Late to Learn New Skills. New Yorker

52. Thornton JE (2002) Myths of aging or ageist stereotypes. Educ Gerontol 28:301-312. doi: $10.1080 / 036012702753590415$

53. Vale MT, Bisconti TL, Sublett JF (2020) Benevolent ageism: Attitudes of overaccommodative behavior toward older women. J Soc Psychol 160:548-558. doi: 10.1080/00224545.2019.1695567

54. Vauclair CM, Borges Rodrigues R, Marques S, Esteves CS, Cunha F, Gerardo F (2018) Doddering but dear ... even in the eyes of young children? Age stereotyping and prejudice in childhood and adolescence. Int J Psychol 53:63-70. doi: 10.1002/ijop.12430

55. Vines J, Pritchard G, Wright P, Olivier P, Brittain K (2015) An Age-Old Problem : Examining the Discourses of Ageing in HCI and Strategies for Future Research. Tochi 22:1-27. doi: $10.1145 / 2696867$

56. Vogt W (2015) Bogardus Social Distance Scale. Dict Stat Methodol 2009. doi: 10.4135/9781412983907.n197

57. Voss P, Wolff JK, Rothermund K (2017) Relations between views on ageing and perceived age discrimination: a domain-specific perspective. Eur J Ageing 14:5-15. doi: 10.1007/s10433-016-0381-4

58. WHO Ageing and health. https://www.who.int/news-room/fact-sheets/detail/ageing-andhealth. Accessed 2 Jan 2021

59. WHO (2006) Constitution of the World Health Organization. World Health Organization

60. WHO (2020) Decade of Healthy Ageing 2020-2030

61. Ylänne-McEwen V (1999) "Young at heart": Discourses of age identity in travel agency interaction. Ageing Soc 19:417-440. doi: 10.1017/S0144686X99007436

62. Zlatev J, Blomberg J (2015) Language may indeed influence thought. Front Psychol 6:1-10. doi: 10.3389 /fpsyg.2015.01631

63. World Population Prospects - Population Division - United Nations. https://population.un.org/wpp/Graphs/DemographicProfiles/. Accessed 5 Jun 2021 